\title{
O ensino de Conteúdos Matemáticos na Educação BÁSICA E AS RELAÇÕES ENTRE AS TEORIAS MATEMÁTICAS E AS APLICAÇÕES PRÁTICAS NO COTIDIANO DOS ESTUDANTES: UM OLHAR DE UM GRUPO DE PROFESSORAS
}

\author{
THE TEACHING OF MATHEMATICAL CONTENTS IN BASIC EDUCATION \\ AND THE RELATIONSHIP BETWEEN MATHEMATICAL THEORIES AND \\ PRACTICAL APPLICATIONS IN STUDENTS' DAILY LIVES: A VIEW FROM A \\ GROUP OF TEACHERS
}

DOI: http://dx.doi.org/10.23926/RPD.2526-2149.2020.v5.n1.p8-27.id563

\section{Loriége Pessoa \\ Bitencourt \\ Doutora em Educação \\ (UFRGS) \\ Professora Efetiva Adjunta \\ da Universidade do Estado \\ de Mato Grosso (UNEMAT) \\ lori.pessoa@hotmail.com}

\section{Amanda Escobar da \\ Silva \\ Especialista em Ensino de \\ Ciências e Matemática \\ (UNEMAT) \\ escobar.amand@gmail.com}

Resumo: Neste artigo são abordados os resultados parciais da pesquisa desenvolvida na Pós-Graduação lato sensu em Ensino de Ciências e Matemática. A questão-problema que tangenciou o processo de pesquisa foi: Os professores que ensinam matemática, participantes da pesquisa, abordam as relações entre as teorias matemáticas e as aplicações práticas existentes no cotidiano dos estudantes e consideram que adquiriram essa competência e habilidade durante a licenciatura que cursaram? Assim, objetivou-se analisar se os professores de Matemática abordam, em suas ações pedagógicas, as relações entre as teorias matemáticas e as aplicações práticas existentes no cotidiano e se consideram que adquiriram essa competência e habilidade durante a licenciatura que cursaram. Para tanto, foi desenvolvida uma pesquisa qualitativa, com dados coletados através de um questionário aplicado a um grupo de cinco professoras que ensinavam Matemática na Educação Básica, as quais eram graduadas na licenciatura em Matemática da UNEMAT/ Cáceres e cursavam a referida Pós-Graduação lato sensu em que a pesquisa foi realizada.

Palavras-chave: Educação Matemática. Ensino-aprendizagem; Relação Teoria-Prática; Currículo de Matemática da Educação Básica.

\begin{abstract}
This article, the partial results of the research carried out in the latu sensu Graduation Program in Sciences and Mathematics Teaching. The problem issue that touched the research process was: Do teachers teaching Mathematics, participating in the research, approach the relations between mathematics theories and the practical applications in the daily life of the students and do they consider that they acquired this competence and expertise during their university degree? Thus, the objective was analyzing if the Mathematics teachers approach upon their pedagogical actions, the relations between mathematics theories and the practical applications of the daily life and if they consider that they acquired this competence and expertise during their university degree. Therefore, a qualitative research was developed with data collected by means of a questionnaire applied to a group of five teachers who taught Mathematics in Elementary School and who took their degree in the Mathematics School at UNEMAT and who also attended the latu sensu Graduation Program.
\end{abstract}

Keywords: Mathematics Education; Teaching-Learning; TheoryPractice Relation; Mathematics Syllabus in Elementary School. 


\section{INTRODUÇÃO}

$\mathrm{Na}$ atualidade, é comum a referência da Matemática como uma ciência abstrata, formal, rigorosa e exata, o que, consequentemente, acarreta uma enorme distorção e dissociação, e, às vezes, até dicotomia entre o que se ensina e aprende na escola com a realidade social na qual os estudantes estão inseridos. Essa situação gera dificuldades, tanto no ensino quanto na aprendizagem dos conteúdos dessa ciência, pois a Matemática ensinada nos currículos escolares, geralmente, não tem significado para quem aprende, pois ela não serve para resolver problemas do seu dia a dia.

Talvez esse contexto de distorções sobre a Matemática possa ser alterado se começarmos a pensar sobre aspectos que ocasionam tal situação, a começar pela formação de professores que ensinam matemática, e a busca, por parte deles, de propostas alternativas para ensinar os conteúdos de Matemática da Educação Básica.

A profissão de professor e a sua principal função, o ensino, precisa deixar de ser um ato de simples transmissão de conhecimentos, em que o professor deposita os conteúdos que ele sabe em um estudante que não sabe, em uma lógica da Educação Bancária rejeitada e criticada por Paulo Freire. $\mathrm{O}$ ensino precisa tornar-se mais complexo, desafiador e criativo, tanto para quem ensina quanto para quem aprende, estimulando professores e estudantes a buscar alternativas para tratar determinados conteúdos, de modo a aprenderem juntos, colaborativamente.

Para que isso aconteça, a formação de professores que ensinam Matemática, tanto a inicial quanto a continuada, precisa ser repensada e praticada, como espaço de formação, interação, reflexão e criticidade sobre o que se ensina e o contexto social no qual professores e estudantes estão inseridos.

O presente artigo traz resultados parciais da pesquisa desenvolvida para a conclusão de um curso de Pós-Graduação lato sensu em Ensino de Ciências e Matemática, em 2017, na qual tínhamos a seguinte questão-problema: Os professores que ensinam Matemática abordam as relações entre as teorias matemáticas e as aplicações práticas existentes no cotidiano dos estudantes e consideram que adquiriram essa competência e habilidade durante a licenciatura que cursaram?

Considerando que constituímos uma amostra de professores limitada e configurada a partir de alguns critérios que, posteriormente, neste artigo estaremos descrevendo, tivemos como objetivo geral para este grupo limitado de docentes participantes desta pesquisa: analisar se os professores de Matemática abordam, em suas ações pedagógicas, as relações entre as 
teorias matemáticas e as aplicações práticas existentes no cotidiano e se consideram que adquiriram essa competência e habilidade durante a licenciatura que cursaram.

Para tanto, foi desenvolvida uma pesquisa de cunho qualitativa, na qual coletamos dados através de um questionário aplicado a um grupo de professoras de Matemática que estavam ativas no exercício da profissão na Educação Básica em diferentes escolas do estado de Mato Grosso, graduadas na licenciatura em Matemática, da Universidade do Estado de Mato Grosso - UNEMAT, e também cursavam a pós-graduação lato senso em Ensino de Ciências e Matemática, especialização está realizada também por uma das autoras desse artigo.

O suporte teórico deste estudo fundou-se em Bitencourt (2017), Beatriz D'Ambrósio (1993), Cunha (1989), D’Ambrósio (1986; 2012), Fiorentini e Nacarato (2012), Freire (1996), Gomes e Rego (2012) e os Parâmetros Curriculares Nacionais (PCN's) do Ensino Fundamental e Médio (1997; 1998; 2000).

Esse aporte teórico nos permitiu abordar a importância de relacionar as teorias de Matemática com as suas aplicações práticas na vida real, de modo contextualizado e atual e, também, mostrar o papel que a formação exerce para o desempenho de uma práxis bemsucedida na Educação Básica.

\section{O Ensino de Matemática no Mundo Contemporâneo: da TeOria À Prática}

A matemática ensinada nas instituições de Educação Básica é resultado de um longo processo de discussões e debates curriculares realizados por gerações de professores, os quais geraram o currículo de Matemática praticado pelos professores na atualidade. Santos e Matos (2017, p. 6) lembram que "o currículo deve ser dinâmico e deve, principalmente, atender à realidade do aluno, deve dar total autonomia ao professor, para que este não sufoque sua criatividade em meio a um currículo congelado e engessado [...]". No entanto, para que essa concepção de currículo seja praticada é necessário que o professor o perceba assim, por essa razão é importante a discussão da relação teoria e prática para o ato de ensinar e aprender.

Assim, quando se pensa sobre o currículo de Matemática ensinado nas escolas, a partir da história da matemática e do seu ensino, percebemos que grande parte dos conteúdos dessa área do conhecimento foi pensada e elaborada para resolver problemas envolvendo situações práticas do cotidiano das pessoas. Segundo os PCN's (BRASIL, 1998), do Ensino Fundamental, a própria história da Matemática mostra que essa ciência foi construída em resposta a perguntas provenientes de diferentes origens e contextos, motivadas por distintos problemas: ora de ordem prática (divisão de terras, cálculo de créditos, etc.), ora vinculados a outras ciências (Física, 
Astronomia, entre outras), e também por complicações relacionadas a investigações internas da própria Matemática. Nesse mesmo sentindo, D’Ambrósio (2012, p. 16) nos esclarece que,

ao longo da história se reconhecem esforços de indivíduos e de todas as sociedades para encontrar explicações, formas de lidar e conviver com a realidade natural e sociocultural. Isso deu origem aos modos de comunicação e às línguas, às religiões e às artes, assim como, às ciências e às matemáticas, enfim a tudo o que chamamos "conhecimento", muitas vezes também chamado "saber".

Assim sendo, fica evidente que o processo de construção histórica da Matemática foi marcado pela então parceria entre a teoria e a prática, em que uma complementa a outra e juntas tornam-se um par perfeito. Essa associação, na atualidade, é uma das alternativas para contemplar um ensino de Matemática com excelência, no qual os alunos consigam aprender a teoria com a visualização da sua prática. Ou seja, observando e problematizando, na prática, a aplicação da teoria que é ensinada, chegando à conclusão de que toda teoria foi gerada a partir de uma prática utilizada para resolver determinada situação-problema.

Na segunda década do século XXI afloraram outras discussões e debates sobre o currículo escolar da Educação Básica, sendo configurada na Base Nacional Comum Curricular (BNCC) que, segundo Santos (2018, p. 134), nos traz "algumas reflexões sobre os objetos de conhecimento que influenciarão diretamente nos processos de ensino e de aprendizagem na Educação Básica, especialmente, no Ensino Fundamental, acerca dos conteúdos de matemática". A mesma autora fala sobre o conhecimento matemático e como ele é apresentado na BNCC: “[...] a BNCC considera que [...] é necessário para todos os alunos da Educação Básica, seja por sua grande aplicação na sociedade contemporânea, seja pelas suas potencialidades na formação de cidadãos críticos, cientes de suas responsabilidades sociais" (BRASIL, 2017, p. 221). Assim, percebemos ser necessário que o professor ensine a Matemática de forma contextualizada, envolvendo outras áreas do conhecimento, pois, desse modo, se configurará como um campo curricular fascinante, democratizando sua aprendizagem na escola.

No entanto, ensinar de forma a conciliar a teoria com a prática demanda que o professor tenha suporte em sua formação para desenvolver habilidades e competências didáticopedagógicas para ensinar, de modo a exercer a sua profissão de forma satisfatória e com sapiência.

Assim, ao considerarmos importante a conciliação entre teoria e prática no currículo escolar de Matemática da Educação Básica, o intuito com esse artigo é refletir sobre a importância de relacionar as teorias dos conteúdos de Matemática com as aplicações práticas 
na vida real dos estudantes de modo contextualizado e também salientar o papel que a formação inicial exerce para o desempenho de uma práxis bem-sucedida na Educação Básica.

Deste modo, considerando que as aplicações dos conteúdos de Matemática ensinados na Educação Básica estão presentes em diversas circunstâncias rotineiras que podem ser transformadas em instrumentos matemáticos para que o estudante aprenda a Matemática de forma significativa e contextualizada e perceba essa ciência em sua vida, permitindo, assim, que aperfeiçoe seu pensar e saber matemático, é que o estudo realizado se torna pertinente.

Dentro dessa perspectiva, D’Ambrósio (2012) afirma que entre a teoria e a prática persiste uma relação dialética que conduz o indivíduo a aprender Matemática, e munido dessa teoria, pratica-la, atingindo, assim, os resultados desejados. Portanto, toda teorização ocorre em condições ideais, e somente na prática serão notados e colocados em evidência certos pressupostos que não podem ser identificados apenas com a teoria.

D’Ambrósio (1986) considera que teoria e prática são indissociáveis e permanentes, nenhuma teoria é final, nenhuma prática é definitiva e não há teoria e prática desvinculadas, sendo relevante relacionar a teoria dos conteúdos matemáticos com sua aplicabilidade na realidade.

Nesse sentido, tanto os PCN's (BRASIL, 1997; 1998; 2000) quanto a recente BNCC (BRASIL, 2017) reconhecem tal importância e caracterizam a Matemática como uma forma de compreender e atuar no mundo. Essa valorização da Matemática revela o quanto essa área do conhecimento é importante, e o tanto de aplicabilidade que ela oferece às demais ciências e a sua presença nas situações do cotidiano, pois o dia a dia possui necessidades que requerem dos alunos o aumento de suas habilidades de natureza prática para lidar com a atividade matemática, o que lhes permite reconhecer problemas, buscar e selecionar informações, tomar decisões.

O elo prática e teoria e vice-versa, segundo D’Ambrósio (2012), é a pesquisa. Nesse mesmo sentido, Freire (1996, p. 14) alerta: "não há ensino sem pesquisa e pesquisa sem ensino". Assim, é relevante que os cursos de graduação, que ofertam e desenvolvem a formação inicial de professores que ensinam Matemática, utilizem a pesquisa como uma das possíveis ferramentas para ensinar, preparando o futuro professor para utilizá-la em suas aulas de Matemática.

Ao se observar e refletir sobre as discussões dos PCN's do Ensino Fundamental (BRASIL, 1998) podemos perceber o papel que o professor deve exercer na mediação do aluno até o saber matemático fazendo a conexão entre a teoria e a prática. 
No entanto, como já mencionamos, para o professor ensinar, relacionando teoria e prática, ele deve estar munido das habilidades e competências necessárias para orientar o estudante para iniciar o processo de transformação. Esse processo envolve o que o estudante aprendeu dos conteúdos matemáticos e o que ele já conhecia, isto é, os conhecimentos culturais e intuitivos contidos em sua bagagem de vida, adquirida na escola ou fora dela, a fim de que encontre, no conhecimento formal e na teoria ensinada na escola — situações de aprendizagens que lhes proporcionem uma aprendizagem com significados compreensíveis e evolutivos dentro da área de Matemática —, meios para explicar o que está acontecendo no seu entorno social através do que está sendo apreendido no ambiente escolar, isto é, relacionar a teoria que é estudada com as necessidades práticas do dia a dia.

Nesse processo de transformação, o professor assume o papel de mediador entre o conhecimento formal que se constitui por meio de teorias Matemáticas e a realidade na qual o estudante está inserido, aproximando teoria e prática, de modo a efetivar a transformação, ou seja, o aluno aprender os conteúdos.

Para que a transformação entre o que o estudante já sabe e o que ele ainda aprenderá, ou seja, um novo conhecimento para este estudante, seja possível, é necessário que o professor conheça a Matemática, tenha conhecimento sobre as teorias matemáticas para melhor desenvolver aplicações práticas das teorizações. Nesse sentido, Cunha (1989) destaca que o domínio do conteúdo está relacionado à prática profissional fora das paredes das instituições de ensino de todos os níveis, pois, por meio dele é definida a possibilidade de relacionar a matéria do ensino com a vida prática, e esse domínio também ajude a produzir exemplos e favoreça a maior instrumentalização do aluno para trabalhar com a realidade.

Dentro dessas perspectivas de discussão, a Educação Matemática nos alicerça para encontrar formas alternativas para qualificar o processo de ensino e aprendizagem da Matemática, pois nela existem algumas tendências que defendem o uso da associação entre o que o aluno já sabe e conhece (realidade de vida) com o que ele vai conhecer e apreender (teorias formais) nas instituições de ensino. Assim, a Educação Matemática do mundo contemporâneo exige do professor habilidades e competências de mediação entre o saber formal e a aplicação que tornem o processo de aprendizagem mais entendível para o estudante.

Segundo os PCN's do Ensino Médio (BRASIL, 2000), para que o educador desempenhe esse papel de mediador entre o conhecimento matemático e o estudante, ele precisa ter conhecimento dos conceitos e procedimentos dessa área e uma concepção de Matemática como 
ciência que não trata de verdades infalíveis e imutáveis, mas como ciência dinâmica, sempre aberta à incorporação de novos conhecimentos.

É importante que os professores compreendam a Matemática como uma disciplina de investigação. Uma disciplina em que o avanço ocorre como consequência do processo de investigação e resolução de problemas. Além disso, é necessário que o professor entenda que a Matemática estudada deve, de alguma forma, ser útil aos estudantes, ajudando-os a compreender, explicar ou organizar sua realidade (D’AMBRÓSIO, 1993).

Nesse contexto de compreensão da Matemática como uma ciência em produção, não pronta e acabada, e sim em constante produção, é necessário debater a formação do professor, pois ela desempenha um papel de fundamental importância, pois

[...] é a área de conhecimentos, investigação e de propostas teóricas e práticas que, no âmbito da Didática e da Organização Escolar, estuda os processos através dos quais os professores - em formação ou em exercício - se implicam individualmente ou em equipe, em experiências de aprendizagem através das quais adquirem ou melhoram os seus conhecimentos, competências e disposições, e que lhes permite intervir profissionalmente no desenvolvimento do seu ensino, do currículo e da escola, com o objetivo de melhorar a qualidade da educação que os alunos recebem. (GARCIA, 1999, p. 26).

Assim, a formação de professores — inicial ou continuada — é um espaço propicio para relacionar teoria e prática de modo a permitir que o futuro professor ou aquele em exercício reflita sobre suas práticas pedagógicas, ressignificando-as de modo a aprender no dia a dia de sala de aula. Isto porque o professor, em seu percurso formativo, pessoal e profissional, "constrói e reconstrói seus saberes conforme a necessidade de sua utilização" (BITENCOURT, 2017, p. 51). Porém, a mesma autora salienta que o modelo da formação de professores que predominou por muitos anos nos curso de licenciaturas, portanto, na formação inicial, "tem sido aquele que se apoia na ideia de acúmulo de conhecimentos ditos teóricos para posterior aplicação ao domínio da prática" (BITENCOURT, 2017, p. 51), o modelo da racionalidade técnica-especialista. Ou seja, dissocia completamente a teoria da prática, separando também a possibilidade da investigação da prática para articular a teoria com a prática.

[...], essa racionalidade que 'molda' esse tipo de formação de professores não representa soluções para problemas educativos porque a realidade educacional e as situações de ensino comportam aspectos que às situam além dos problemas instrumentais, por ser o ensino uma atividade humana, desenvolvida por homens e mulheres que se (re)constroem constantemente, se (re)fazendo a cada nova situação de sala de aula. ((BITENCOURT, 2017, p. 52).

Porém, a racionalidade técnica prepara o professor para transmitir seus conhecimentos de uma forma mecânica, hierárquica e acriticamente. Separa ciência do mundo, reproduz um currículo formatado pelo livro didático, mantendo-se as amarras determinadas pelo Estado, sem 
possível reflexão e criação de um currículo contextualizado e que auxilie o estudante a compreender o mundo que o cerca.

Esse modelo foi caracterizado como limitante para a formação de professores. Assim, se fez necessária outra racionalidade para a formação de professores, e ela foi preconizada pelo Parecer CNE/CP $n^{\circ}$ 9/2001 (BRASIL, 2001) que trata sobre as Diretrizes Curriculares Nacionais para a Formação de Professores implementada nas Instituições de Educação Superior - IES brasileiras, que é racionalidade prática-reflexiva, e que, desde a formação inicial do professor, integre teoria e prática, isto é, os conhecimentos científicos aprendidos na Universidade com as práticas de sala de aula em uma escola real, com todas as situações de ensino. A formação de professores, sob essa racionalidade, é

vista segundo o modelo reflexivo e artístico, tendo por base a concepção construtivista da realidade com a qual o professor se defronta, entendendo que ele constrói seu conhecimento profissional de forma idiossincrática e processual, incorporando e transcendendo o conhecimento advindo da racionalidade técnica. (MIZUKAMI et al., 2012, p.15)

Esse outro modelo permite uma formação com o pé na escola, ou seja, uma formação vivida a partir do contexto profissional para o qual o futuro professor se prepara para ensinar, percebendo as necessidades de conciliar teoria e prática; questionando criticamente a formação na Universidade, a teoria, com a formação em ambientes profissionais reais, com práticas de compreensão da profissão de professor que ensina Matemática, indagando o porquê de se ensinar e aprender determinadas teorias.

Mas será que os cursos de formação de professores, mesmo na contemporaneidade, tendo um currículo configurado na lógica da racionalidade prático-reflexiva, possibilitam que os licenciandos desenvolvam habilidades e competências suficientes para ensinar os conteúdos Matemáticos relacionando teoria e prática?

Esse questionamento se faz necessário, pois, apesar de as Diretrizes Curriculares Nacionais para a Formação de Professores preconizarem que se relacione teoria e prática, a maioria dos cursos de formação inicial de professores que ensinam Matemática reduz a função de ensinar do professor a uma perspectiva mecânica e descontextualizada (CUNHA, 1989). Ou seja, o ensino que os docentes recebem durante a graduação não os prepara para a realidade da sala de aula. Gomes e Rego (2012) corroboram esse pensamento ao dizerem que, apesar das mudanças que vêm ocorrendo no setor educacional, a maioria dos cursos de formação de professores de Matemática prepara os professores para continuar a ensinar em sala de aula, com práticas retrógradas e centradas no modelo tecnicista desenvolvido de maneira empírica. Assim, 
os processos de ensino instalados nas instituições escolares representam um formato instalado pelos cursos de licenciaturas difícil de superar. Por essa razão, é necessário, além de mudanças efetivas nos cursos de formação inicial, estabelecer programas de formação continuada para os professores dos diversos níveis de ensino, de modo que sejam construídas novas experiências e reflexões sobre formas mais eficientes de ensinar Matemática.

No que diz respeito à formação continuada de professores que ensinam Matemática, Fiorentini e Nacarato (2005) destacam que as iniciativas ocorridas, entre as décadas 1970 e 1990, foram pouco eficazes na mudança dos saberes, das concepções e da prática docente nas escolas, por várias razões. A principal delas é que esses cursos de formação continuada promoviam uma prática de formação descontínua em relação: à formação inicial dos professores; ao saber experiencial dos professores, os quais não eram tomados como ponto de partida da formação continuada; aos reais problemas e desafios da prática escolar; e, sobretudo, porque eram ações pontuais e temporárias, tendo data marcada para começar e terminar. Muitas destas críticas têm como alvo o caráter excessivamente teórico dos cursos e a desconsideração do conhecimento prático do professor, trazendo, com isto, uma dificuldade maior de chegar até as escolas e às práticas pedagógicas de professores.

Essa dicotomia entre o teórico e o prático existente nos programas de formação docente também é discutida por Martins (1999), que aponta uma crise no saber que o construiu. A autora afirma que a convicção de que as situações-problema vivenciadas pelos professores podem ser tratadas recorrendo-se ao corpo de conhecimentos, aos saberes pontualmente estabelecidos e aos modos usuais de sua aquisição não atendem às exigências do enfrentamento das situações que se apresentam ao professor. Também afirma que a seleção teórica adotada pela universidade não tem familiaridade com o específico da escola, tornando-se inadequada para a compreensão da escola. A autora ainda destaca que as descrições teóricas preservam um caráter de generalidade, enquanto que as questões práticas têm como característica a especificidade de uma situacionalidade complexa. São incontáveis as situações de ensinar em que os professores se defrontam com dificuldades de aprendizagem decorrentes de situações complexas, caracterizadamente particulares, com exigências específicas de temporalidade e espacialização do sujeito da aprendizagem.

Beatriz D’Ambrósio (1993), já na década de 1990, salientava a necessidade de modificação nos programas de formação de professores para que fossem oferecidos ao futuro docente os tipos de experiências necessárias para que ele reconceituasse sua visão do que vem a ser a Matemática e do que constitui a legítima atividade matemática. Essas experiências 
necessárias, segundo a autora, são: experiências matemáticas, o futuro professor de Matemática deve aprender novas ideias matemáticas de forma alternativa; e, experiência com os estudantes — futuros professores constroem seu conhecimento sobre o ensino da Matemática através de suas experiências com o ensino.

Para Freire (1996), a habilidade de refletir criticamente sobre a própria ação pedagógica é um requisito para que a teoria não vire uma conversa sem conteúdo e a prática não se transforme em "ativismo”. Sob esse enfoque, Martins (1999) considera indiscutível o valor dos conteúdos culturais e valoriza uma didática implícita a esses conteúdos e sua banalização pela extrema simplificação, o que desvirtua o saber a que a didática se aplica. Essas simplificações da intervenção predispõem o docente ao ativismo, apontando para a dificuldade em formular a área pedagógica como de pesquisa, pois o ato de pesquisar oferece ao educador um pensamento mais crítico e reflexivo sobre a sua própria ação pedagógica para que ele possa reelaborar suas ações educativas, visando sempre o melhor desempenho do seu processo de ensinar e aprender.

Ao refletir sobre quais sugestões poderia propor para contribuir para a formação e a educação dos professores, Cunha (1989, p. 151) afirma:

[...] a formação do educador é um processo, acontecendo no interior das condições históricas em que ele mesmo vive. Faz parte de uma realidade concreta determinada, que não é estática e definitiva. É uma realidade que se faz no cotidiano. Por isso, é importante que esse cotidiano seja desvendado. O retorno permanente da reflexão sobre sua caminhada como educando e como educador é que pode fazer avançar o seu fazer pedagógico. [...] A prática é que dá sentido às inquietações do ser humano. É preciso que a formação pedagógica se faça sobre ela. O significado dos estudos na área da educação depende da capacidade de auscultar o momento do educando, que transparece principalmente por seu discurso. Nele há a expressão de suas experiências condições de vida, interesse e aspirações. É preciso partir daí.

É notável a defesa para que os cursos de formação trabalhem dentro de uma perspectiva contextualizada, levando em consideração o meio no qual o indivíduo a ser formado está inserido e o ambiente em que ele vai adentrar para atuar como profissional da educação.

Diante de tudo o que foi elucidado até aqui, pode-se afirmar que aliar a teoria da Matemática com sua aplicação na prática se constitui uma alternativa para reduzir ou eliminar (isso com muito trabalho e perseverança) o paradigma de que a Matemática é complicada, obsoleta para a vida, sombria e enigmática para tantas pessoas.

\section{Caminho Metodológico Trilhado}

$\mathrm{Na}$ investigação realizada optamos pela pesquisa qualitativa. Essa modalidade de pesquisa tem o foco voltado para o ser humano, com toda a sua complexidade e na sua inserção 
e interação com o ambiente social, cultural e natural. A filosofia do pesquisador resulta do referencial teórico, sendo este intrínseco ao processo (D’AMBRÓSIO, 2012).

O lócus de pesquisa foi o curso de pós-graduação lato sensu em Ensino de Ciências e Matemática, desenvolvido na Universidade do Estado de Mato Grosso, durante os anos de 2015 a 2017, e, nele, como participantes da pesquisa, os pós-graduandos que concluíram o curso, defenderam suas monografias, sendo, ao todo, 13 participantes, entre os quais havia licenciados em: Matemática, Física, Química e Ciências Biológicas, em diferentes IES.

Como nos interessava analisar se os professores de Matemática, em suas ações pedagógicas para ensinar Matemática na Educação Básica, abordam as relações entre as teorias matemáticas e as aplicações práticas no cotidiano, e se consideram que adquiriram essa competência e habilidade durante a licenciatura cursada, ou seja, refletir sobre habilidades e competências dos professores para ensinar Matemática, relacionando teoria-prática, e se esses professores compreendem que a formação inicial desenvolve tais habilidades e competências, adotamos alguns critérios para a seleção dos participantes da pesquisa.

Os critérios para a constituição da amostra dos participantes foram: ter realizado a formação inicial no curso de Licenciatura em Matemática da UNEMAT/Cáceres; estar lecionando a disciplina de Matemática na Educação Básica em 2017; estar desenvolvendo a pós-graduação lato sensu no Ensino de Ciências e Matemática. Por conta desses três critérios, os sujeitos participantes desta investigação compõem um grupo de cinco professoras, em que no Quadro 1, a seguir especificamos algumas características que demonstram o município onde residem e os níveis e modalidades da educação Básica que lecionam:

Quadro 1 - Características das participantes do estudo - em 2017

\begin{tabular}{|c|c|c|}
\hline NOME FICTÍCIO & RESIDIA no município de: & NÍVEL QUE LECIONAVA \\
\hline Prof. $^{\text {a }} 1$ & Lambari D’Oeste & Fundamental, Médio e EJA \\
\hline Prof. $^{\text {a }} 2$ & Mirassol D’Oeste & Fundamental \\
\hline Prof. $^{\text {a }} 3$ & São José dos Quatro Marcos & Fundamental \\
\hline Prof. $^{\text {a }} 4$ & Cáceres & Ensino Médio \\
\hline Prof. $^{\text {a }} 5$ & Cáceres & EJA \\
\hline
\end{tabular}

Fonte: Da pesquisa.

Para a produção dos dados da referida pesquisa, utilizamos um questionário, composto por um conjunto de questões para serem respondidas por escrito pelos pesquisados. Essa escolha se justifica pelo fato de que a aplicação do questionário não exige o contato direto do pesquisador com os investigados e, portanto, os questionários foram enviados e devolvidos via e-mail. 
O questionário foi composto por uma série de perguntas abertas. Essa modalidade de perguntas não objetivas permite ao pesquisador captar algumas informações não previstas. Além disso, as questões abertas prestam-se melhor para a coleta de informações qualitativas (FIORENTINI; LORENZATO, 2012), como é o caso deste estudo.

Os dados foram organizados e analisados em categorias de análise.

\begin{abstract}
A categorização significa um processo de classificação ou de organização de informações em categorias, isto é, em classes ou conjuntos que contenham elementos ou características comuns. Nesse processo, existem alguns princípios que devem ser observados pelo pesquisador. O primeiro deles é que o conjunto das categorias deve estar relacionado a uma ideia ou conceito central capaz de abranger todas as categorias. (FIORENTINI; LORENZATO, 2012, p. 134).
\end{abstract}

Segundo Fiorentini e Lorenzato (2012), as categorias podem receber três classificações: definidas a priori, emergentes ou mistas. $\mathrm{Na}$ análise desta pesquisa as categorias foram feitas mediante um processo interpretativo-direto após o recebimento do questionário respondido, portanto, foi adotada a categoria emergente, pois os dados nos auxiliam a encontrá-las.

Ainda sob o ponto de vista de Fiorentini e Lorenzato (2012), utilizar categorias de análise auxilia a destacar aspectos relevantes da pesquisa, contribuindo para responder a problematização, por isso, a construção das categorias deve atender às solicitações que emanam da questão problema.

Enfim, a metodologia aqui descrita foi utilizada para realizar a coleta e a análise dos resultados da pesquisa, no intuito de, a partir dos objetivos traçados/estabelecidos, obter respostas para as indagações desta pesquisa.

Interpretação e Análise dos Dados

Neste tópico, apresentamos as interfaces dos dados produzidos com o aporte teórico, trazendo a discussão e a análise dos resultados. Conforme já expomos, os dados foram produzidos por meio de um questionário aplicado a um grupo de cinco professoras de Matemática, desta forma, os resultados alcançados se referem a este grupo de professoras e não podem ser generalizados.

Com o intuito de conhecer a importância dada por essas professoras à relação teoria $\mathrm{e}$ prática para ensinar Matemática, questionamos: "Você considera importante relacionar a teoria dos conteúdos de Matemática com as suas respectivas práticas nas aulas de Matemática? Por quê?"

As cinco professoras questionadas consideram importante a relação entre as teorias contidas nos conteúdos com as possíveis aplicações na realidade da vida dos seus estudantes para que o aprendizado seja mais significativo. Para elas, as aulas ficam mais interessantes e 
diferenciadas, e aumenta o interesse do estudante em estudar o conteúdo. Esse reconhecimento dialético entre teoria e prática (D’AMBRÓSIO, 2012), por parte das professoras, é muito importante, pois caracteriza a Matemática como um meio para a compreensão da realidade. Os PCN'S (1997) orientam os professores para que abordem os multiusos que o conhecimento matemático possui ao afirmar que esse saber não foi só construído por cientistas, matemáticos ou engenheiros, mas por todos os que utilizam as habilidades de contar, medir, localizar, jogar, explicar, entre outras, as quais aproximam a realidade em que a sociedade está inserida do saber matemático escolar.

Com a intenção de verificar se as professoras pesquisadas adotam, em suas aulas, a teoria e a prática de forma relacional e complementar, perguntamos: "No desenvolvimento de suas aulas de Matemática, você consegue estabelecer a relação entre a teoria dos conteúdos de Matemática com as suas aplicações práticas na realidade de vida dos alunos? Justifique.”. A maioria das professoras, quatro delas, responderam que às vezes ou depende da situação, justificando ou descrevendo de formas diferentes, e somente uma delas respondeu que não.

As professoras que responderam que conseguem estabelecer a relação, afirmam que dedicam mais tempo à teoria, e em alguns momentos ou com algumas turmas fazem essa associação entre a teoria e a prática. Sob esse aspecto, destacamos duas respostas:

“Às vezes, consigo visualizar as aplicações, outras não” (Prof. 1- QP2).

"Prezo mais pela teoria e abordo as aplicações práticas em ocasiões especiais, estabelecendo a relação teoria e prática nas turmas em que quero chamar mais atenção" (Prof.5-QP2).

Observamos que as professoras destacam a importância dada por elas a teoria, o que demonstram dificuldade para ensinar os conteúdos matemáticos usando a relação teoria e prática, já que as separam no grau de importância atribuído a elas. Isso é comum acontecer, pois o currículo de Matemática da Educação Básica já vem determinado pelo Estado e o professor se sente pressionado a cumpri-lo dentro de um cronograma preestabelecido, se preocupando, ou pelo menos dando mais ênfase, à teoria dos conteúdos Matemáticos, de forma a transmitir aquela teoria pronta e acabada, sem contextualizá-la.

Outra professora respondeu:

"na maioria das vezes não consigo efetuar a relação entre teoria e prática devido às incumbências externas e o número de aulas de matemática por semana para tanto conteúdo". (Prof.4-QP2)

A resposta desta professora nos traz mais elementos sobre a relação teórica e prática para ensinar que dificultam, que são os fatores externos ao professor, que são a pressão diária 
feita pelos órgãos de controle ao professor que faz com que ele prevalece a quantidade de conteúdos ensinados a qualidade deste ensino, que pode gerar uma aprendizagem para a vida. Para Beatriz D’Ambrósio (1993), é importante que os "novos" professores compreendam a Matemática como uma disciplina de investigação, sempre se fazendo na relação entre teoria e prática, de forma a torná-la teoria-prática de modo indissociada e inseparável, pois assim, o próprio professor irá perceber que quando ensina através da investigação, ao buscar, ao problematizar a teoria, o estudante descobrirá formas de aplicá-los e assim aprenderá. Uma disciplina em que o avanço ocorre em consequência do processo de investigação e resolução de problemas. Além disso, é necessário que o professor entenda que a Matemática estudada deve, de alguma forma, ser útil aos estudantes, ajudando-os a compreender, explicar ou organizar sua realidade.

Já foi mencionado, anteriormente, que as participantes da pesquisa admitem a importância de tal relação, assim sendo, eis a questão: por que a maioria dessas educadoras não consegue realizar, em suas ações educativas, uma abordagem que realize a associação entre a teoria e a prática? Na concepção de Cunha (1989), a resposta a essa pergunta é que a maioria dos cursos de formação reduz o ensino como um ato mecânico e descontextualizado. Para essa autora, as instruções que os docentes recebem durante a graduação não os prepara para a realidade da sala de aula, mesmo no início da profissão.

Essa perspectiva encontra defesa nos estudos de Gomes e Rego (2012), quando dizem que a maioria dos cursos de formação de professores de Matemática continua utilizando, em sala de aula, práticas retrógradas e centradas no modelo tecnicista, e essas mesmas práticas são reproduzidas na Educação Básica pelos licenciados.

Com o objetivo de conhecer as dificuldades que as educadoras participantes da pesquisa encontram para trabalhar em suas aulas a teoria dos conteúdos matemáticos com as suas aplicações práticas na vida dos alunos foi questionado: "Quais dificuldades você encontra para relacionar teoria e prática em suas aulas de Matemática?"

As respostas foram compostas por diferentes posições, aparecendo mais de uma justificativa, assim, as categorizamos em grupos, não excludentes, sendo eles: (1) não encontra aplicação prática para todos os conteúdos com rapidez, com isso é necessário maior dedicação; (2) possui insegurança com o domínio de conteúdo, devido à inexperiência na profissão quando se depara com conteúdo que irá trabalhar pela primeira vez; (3) pouco tempo disponível para cumprir a programação curricular, porque a lista de conteúdo programada é muito extensa e o tempo disponível na carga horária das aulas é curto; (4) trabalha com várias realidades de vida, 
portanto, não consegue atingir todos os alunos com uma mesma abordagem, numa mesma turma. Essas categorias constam no Quadro 2.

Quadro 2 - Respostas obtidas para justificar o ato de não ensinar conciliando teoria e prática

\begin{tabular}{|l|c|}
\hline \multicolumn{1}{|c|}{ Categorias } & $\begin{array}{c}\text { Quantidade de respostas que } \\
\text { evidenciaram as categorias }\end{array}$ \\
\hline $\begin{array}{l}\text { (1) Não encontra aplicação prática para todos os conteúdos com rapidez, com } \\
\text { isso é necessário maior dedicação; }\end{array}$ & 01 \\
\hline $\begin{array}{l}\text { (2) Possui insegurança com o domínio de conteúdo, devido à inexperiência na } \\
\text { profissão quando se depara com conteúdo que irá trabalhar pela primeira vez; }\end{array}$ & 02 \\
\hline $\begin{array}{l}\text { (3) Pouco tempo disponível para cumprir a programação curricular, porque a } \\
\text { lista de conteúdo programada é muito extensa e o tempo disponível na carga } \\
\text { horária das aulas é curto; }\end{array}$ & 03 \\
\hline $\begin{array}{l}\text { (4) Trabalha com várias realidades de vida, portanto, não consegue atingir } \\
\text { todos os alunos com uma mesma abordagem numa mesma turma. }\end{array}$ & 01 \\
\hline
\end{tabular}

Fonte: autoria própria a partir dos dados produzidos a partir do questionário

Talvez essa variação de respostas, categorizadas e mostradas no Quadro 2, ocorra pelo fato de as professoras terem experiências na Educação Básica bastante diferenciadas, ou pelas localidades onde residem pelos diferentes contextos sociais nos quais as escolas estão inseridas, pelas distintas orientações curriculares, peculiar de cada rede de educação, municipal ou estadual, e trabalham, pelos níveis de educação diferenciados ou ainda pelas modalidades de Educação, pois duas professores declararam ensinar na Educação de Jovens e Adultos (EJA) (Quadro 1).

No texto dos PCN's (BRASIL, 1998) do Ensino Fundamental encontramos um argumento que avaliamos importante a ser considerado para analisar as respostas evidenciadas no Quadro 2. Conforme o documento que orienta o professor a ensinar relacionando teoria e prática, o professor deve estar munido de habilidades e competências que permitam estabelecer situações didáticas, em que ele próprio assume o papel de mediador, ensinando por meio da pesquisa, problematizando as situações complexas que apareçam em sala de aula, e não apresentando respostas prontas ao estudante. Essa atitude possibilita ao estudante exercitar a habilidade e a competência de pensar para visualizar a aplicabilidade de tais conhecimentos, relacionando teoria e prática. Assim, é necessário que o professor conheça a Matemática de maneira aprofundada, para melhor desenvolver aplicações práticas dos conteúdos, fazendo assim, as teorizações (PCN'S, 1998). Essa obrigatoriedade contida nos Parâmetros Curriculares é valorizada por Cunha (1989).

A última questão foi dedicada a desvendar o valor que essas professoras, participantes da pesquisa, atribuem ao papel da formação inicial no seu exercício de ensinar na Educação Básica. 
Dentre as respostas obtidas, três $(60 \%)$ das professoras consideram que não receberam preparo suficiente na formação inicial para ensinar conciliando teoria e prática. No entanto, reconhecem que houve alguns fatores no curso de licenciatura que contribuíram para lidar com a realidade da sala de aula, pois, segundo elas, já passaram por situações que não souberam como agir.

Essas mesmas três professoras caracterizaram o currículo da formação inicial desenvolvida por elas como conteudista, enfatizando, nas disciplinas, muita teoria e pouca relação com a prática. Por outro lado, apesar das falhas que apontaram, também consideram que algumas disciplinas e professores tiveram um papel diferencial e contribuíram bastante para o exercício da profissão e semearam a importância de relacionar teoria e prática.

Essa dicotomia entre o teórico e o prático existente nos programas de formação docente é discutida por Martins (1999), e já foi evidenciada neste texto, ao destacar que a seleção teórica do currículo das licenciaturas desenvolvidas nas Universidades não têm familiaridade com o específico da escola. Há, aí, um distanciamento entre a Escola Ideal - tratada pela Universidade - e a Escola Real, vivida, posteriormente, pelos professores, após sua formatura na Universidade. A autora destaca também que nas licenciaturas as teorias preservam um caráter de generalidade, enquanto que as questões práticas trazem a especificidade de uma situacionalidade complexa.

Em resposta a essa mesma pergunta, duas professoras, representando 40\%, afirmaram que não foram preparadas devido à falta de familiaridade da universidade com a escola, e apontaram a falta de aproximação entre a universidade e a realidade escolar, e também sentem a necessidade de haver mais disciplinas voltadas para a prática na sala de aula. Aqui fica claro que as professoras investigadas consideram que a formação que desenvolveram não as preparou o suficiente para assumir a sala de aula e muito menos para encontrar alternativas para ensinar relacionando teoria-prática.

\section{CONSIDERAÇÕES FINAIS}

Vivemos um momento histórico mundial de muitas transformações, as quais afetam as relações em várias dimensões e nos fazem repensar sobre o papel do professor na vida dos estudantes. Quando pensamos a Matemática como uma ciência viva e, em constante transformação e essa ciência, portanto, teoria produzida cientificamente, é testada por cientistas em situações práticas, demonstrando inclusive sua relevância a partir da sua aplicabilidade, chegamos à conclusão que qualquer ciência é produzida na relação teoria-prática. 
No entanto, só conseguimos perceber a relação teoria-prática de modo indissociada, se problematizamos essa ciência, ficando então a pergunta: Será que essas transformações que a ciência gera na sociedade, alteraram a forma de ensinar e, portanto, de aprender? Por que a ciência Matemática é vista como pronta, acabada, sendo reproduzida pelo professor acriticamente e, na maioria das vezes, não sendo aprendida pelos estudantes?

Apesar dessas questões não serem o foco deste artigo, elas estão ligados às dificuldades que o educador do século XXI se depara no exercício da profissão e também nas práticas pedagógicas que esse profissional consegue adotar em sala de aula.

A pesquisa aqui realizada, respaldada em teóricos/pesquisadores da Educação, mostra sua relevância para o ensino e para a aprendizagem da Matemática, para o desenvolvimento de situações didáticas, em que ocorra a associação entre o que está sendo afirmado pela teoria com o que está sendo utilizado nas situações práticas do dia a dia.

Em contrapartida, o estudo do Parecer CNE/CP 9/2001 e das Diretrizes Curriculares Nacionais para a formação inicial e continuada dos Profissionais do Magistério da Educação Básica, nos fornece a possibilidade de destacar a necessária discussão sobre os cursos de formação de professores, tanto os de formação inicial como a continuada, por possuírem lacunas que dissociam a teoria e a prática, que distanciam o espaço de formação das realidades da escola e, assim, não oferecem aos seus estudantes em processo de formação, habilidades e competências suficientes para dominarem um leque mais diversificado de metodologias para ensinar. Tanto é que no final do ano de 2019 temos a proposição da Resolução CNE/CP nº 2, de Dezembro de 2019, que define as Diretrizes Curriculares Nacionais para a Formação Inicial de Professores para a Educação Básica e institui a Base Nacional Comum para a Formação Inicial de Professores da Educação Básica (BNC-Formação), trazendo como centro de todo o currículo da formação a relação entre teoria-prática, a formação no espaço profissional e etc. (BRASIL, 2019)

Com esta pesquisa, no universo pesquisado, foi constatado que, apesar de as docentes admitirem a importância de aliar teoria e prática, também assumem não realizar tal metodologia e, na maioria das vezes, elencam diversos motivos: pouco tempo disponível, não dominar o conteúdo, desinteresse do aluno, etc. Em concomitância, afirmam não terem sido preparadas na graduação que realizaram para lidar com toda a complexidade existente no cenário escolar.

Nesse contexto, fica evidente que para os pesquisadores/teóricos utilizados nesta pesquisa não há teoria e prática desvinculadas, pois, para eles, uma legitima a outra. Entretanto, 
nota-se que para as participantes da pesquisa esse conceito não está claro ou não foi aprendido, pois, em suas respostas, mostraram que concebem teoria e prática desvinculadas, dicotômicas.

O caminho apontado, como um dos passos para o fim desse túnel tão problemático, são os cursos stricto sensu que oferecem formação continuada e têm como foco proporcionar métodos de ensino-aprendizagem alternativos, propiciando, assim, conhecimentos mais elaborados aos profissionais da educação.

Portanto, diante de tudo o que foi elucidado nesta pesquisa, percebe-se que para haver uma real melhora e preparo dos profissionais que irão trabalhar na Educação Básica, os primeiros passos para tal mudança deverão ser iniciados desde a formação inicial/graduação, pois a maioria dos docentes irá para a sala de aula logo após o término da graduação.

Assim, concluímos que as Educadoras de Matemática, participantes desta pesquisa, afirmam não sair preparadas da graduação para assumir uma sala de aula e toda a complexidade dessa responsabilidade. Foi constatado que não possuem domínio das teorias e aplicações matemáticas, e não sabem lidar com as diversidades que o ambiente escolar detêm. Em concomitância, apesar de esses profissionais terem consciência da importância de associar a teoria à prática em Matemática, não conseguem, na maioria das vezes, fazer ou oferecer meios para que o aluno estabeleça uma relação entre o que está sendo dito na teoria que envolve determinado conteúdo Matemático escolar com o que os estudantes vivenciam diariamente no seu convívio em sociedade.

\section{REFERÊNCIAS}

BITENCOURT, Loriége Pessoa. Aprendizagem da Docência do Professor Formador de Educadores Matemáticos. Curitiba: CRV, 2017.

BRASIL, Ministério da Educação e Cultura - MEC, Secretaria de Educação Fundamental. Parâmetros Curriculares Nacionais: Matemática. Brasília: MEC / SEF, 1997.

BRASIL, Ministério da Educação e Cultura - MEC, Secretaria de Educação Fundamental. Parâmetros Curriculares Nacionais: Matemática. Brasília: MEC / SEF, 1998.

BRASIL, Ministério da Educação e Cultura - MEC, Secretaria de Educação Fundamental. Parâmetros Curriculares Nacionais Ensino Médio. Brasília: MEC / SEF, 2000.

BRASIL, Parecer CNE/CP 9/2001 - Diretrizes Curriculares Nacionais para a Formação de Professores da Educação Básica, em nível superior, curso de licenciatura, de graduação plena Homologado pelo despacho do Ministro em 17/1/2002, publicado no Diário Oficial da União de 18/1/2002, Seção 1, p. 31. 2001.

BRASIL, Resolução No 2, de $9^{\circ}$ de junho de 2015. Define as Diretrizes Curriculares Nacionais para a formação inicial e continuada dos Profissionais do Magistério da Educação 
Básica. 2015. Disponível em :

http://portal.mec.gov.br/index.php?option=com_docman\&view=download\&alias $=17625$ parecer-cne-cp-2-2015-aprovado-9-junho-2015\&category_slug=junho2015pdf\&Itemid=30192. Acesso em: Janeiro de 2016.

BRASIL. Base Nacional Comum Curricular. $3^{\text {a }}$ versão. Brasília: Ministério da Educação. 2017. Disponível em: http://basenacionalcomum.mec.gov.br/images/BNC C_20dez_site.pdf. Acesso em: 01 de Outubro de 2019.

BRASIL. Resolução CNE/CP N ${ }^{\circ}$ 2, de 20 de dezembro de 2019. Brasília. Ministério da Educação. Conselho Nacional de Educação. Conselho Pleno. Define as Diretrizes Curriculares Nacionais para a Formação Inicial de Professores para a Educação Básica e institui a Base Nacional Comum para a Formação Inicial de Professores da Educação Básica (BNC-Formação). 2019. Disponível em: http://portal.mec.gov.br/docman/dezembro-2019pdf/135951-rcp002-19/file. Acesso em: 03 de Fevereiro de 2020.

CUNHA, Maria Isabel. O bom professor e sua prática. Campinas, SP: Papirus, 1989. (Coleção Magistério: Formação e Trabalho Pedagógico).

D’AMBRÓSIO, Beatriz. Formação de professores de Matemática para o século XXI: o grande desafio. Pro-Posições. v. 4 n. 1 [10] março de 1993.

D’AMBROSIO, Ubiratan. Educação para uma Sociedade em Transição. $2^{a}$ edição. Natal RN: Editora da 143 Maria José Costa dos Santos Horizontes, v. 36, n. 1, p. 132-143, jan./abr. 2018 UFRN, 2011.

D’AMBROSIO, Ubiratan. Educação Matemática: da teoria à prática. 23ª ed. Campinas, SP: Papirus, 2012. (Coleção Perspectivas em Educação Matemática).

D’AMBROSIO, Ubiratan. Da realidade à ação: reflexões sobre educação e matemática. São Paulo: Summus; Campinas. Ed. da Universidade Estadual de Campinas, 1986.

FIORENTINI, Dario.; LORENZATO, Sergio. Investigação em Educação Matemática: percursos teóricos e metodológicos. $3^{\text {a }}$ ed. rev. Campinas, SP: Autores Associados, 2012. (Coleção formação de professores).

FIORENTINI, Dario.; NACARATO. Adair Mendes. (Org.). Cultura, formação e desenvolvimento profissional de professores que ensinam matemática. São Paulo: Musa Editora. Campinas, SP: GEPFPM-PRAPEM-FE/UNICAMP, 2005.

FREIRE, Paulo. Pedagogia da Autonomia: saberes necessários à prática educativa. São Paulo: Paz e Terra, 1996.

GOMES, Jacqueline Oliveira de Melo; REGO, Rômulo Marinho do. A Formação do Professor de Matemática: Um Estudo sobre a Implantação de Novas Metodologias nos Cursos de Licenciaturas de Matemática da Paraíba. Disponível em:

https://www.sbem.com.br/files/ix_enem/.../CC02629181456T.rtf. Acessado em: 21/05/2016.

GARCIA, Carlos Marcelo. Formação de Professores: Para uma mudança educativa. Porto: Porto Editora, 1999. 
MARTINS, Maria Anita Viviani. O teórico e o prático na formação de professores. In: CAPELLETI, Isabel F.; LIMA, Luiz A. N. (Orgs.). Formação de Educadores-pesquisas e estudos qualitativos. São Paulo: Olho d'água, 1999.

MIZUKAMI, Maria da Graça. N. et al. Escola e aprendizagem da docência: processos de investigação e formação. São Carlos: EDFSCAR, 2002.

SANTOS, Maria José Costa dos. O currículo de matemática dos anos iniciais do ensino fundamental na base nacional comum curricular (BNCC): os subalternos falam? In. Horizontes, v. 36, n. 1, p. 132-143, jan./abr. 2018.

SANTOS, Maria José Costa dos; MATOS, Fernanda Cíntia Costa. A insubordinação criativa na formação contínua do pedagogo para o ensino da matemática: os subalternos falam? REnCiMa, v. 8, n. 4, p. 11-30, 2017. Disponível em: http://revistapos.cruzeirodosul.edu.br/index.php/rencima/issue/view/59. Acesso: dia 21 de março de 2018.

Recebido em: 17 de outubro de 2019.

Aprovado em: 6 de abril de 2020. 